13. Saravanan, V., Parthiban, K. T., Thirunirai, R., Kumar, P., Vennila, S. and Umesh Kanna, S., Comparative study of wood physical and mechanical properties of Melia dubia with Tectona grandis at different age gradation. Res. J. Rec. Sci., 2014, 3, 256263.

14. Nguyen, V. L., Estimation of biomass for calculating carbon storage and $\mathrm{CO}_{2}$ sequestration using remote sensing technology in Yok Don National Park, Central Highlands of Vietnam. J. Vietnam. Environ., 2012, 3(1), 14-18.

15. Pandya, I. Y., Salvi, H., Chahar, O. and Vaghela, N., Quantitative analysis on carbon storage of 25 valuable tree species of Gujarat, incredible India. Indian J. Sci. Res., 2013, 4(1), 137.

16. Carmi, I., Kronfeld, J. and Moinester, M., Sequestration of atmospheric carbon dioxide as inorganic carbon in the unsaturated zone under semi-arid forests, 2017, arXiv:1702.05249.

17. Tripathi, M. and Joshi, H., Carbon flow in Delhi urban forest ecosystems. Scholars Res. Libr., 2015, 6(8), 13-17.

18. Ashalatha, A, Divya, M. P. and Ajayghosh, V., Development of suitable Melia dubia based agroforestry models for higher productivity. Madras Agric. J., 2015, 102(7-9), 264-267.

19. Vanlalngurzauva, T., Dhara, P. K., Banerjee, H. and Maiti, S., Growth and productivity of different intercrops grown under gamhar (Gmelina arborea) based agro forestry system. Indian J. Agrofor., 2010, 12, 105-108.

20. Rizvi, R. H., Dhyani, S. K., Yadav, R. S. and Singh, R., Biomass production and carbon stock of poplar agroforestry systems in Yamunanagar and Saharanpur districts of northwestern India. Curr. Sci., 2011, 100(5), 736-742.

21. Saravanan, V., Parthiban, K. T., Kumar, P. and Marimuthu, P., Wood characterization studies on Melia dubia cav. for pulp and paper industry at different age gradation. Res. J. Rec. Sci., 2013, 2, $183-188$.

22. Deswal, A. K. and Nandal, D. P. S., Growth and yield of wheat (Triticum aestivum) under varying levels of irrigation and fertilizer in eucalyptus based agri-silviculture system. Indian J. Agrofor., 2008, 10(1), 10-14.

23. Prasad, J. V. N. S. et al., On-farm evaluation of two fast growing trees for biomass production for industrial use in Andhra Pradesh, southern India. New For., 2011, 42(1), 51-61.

24. Kumar, A., Kumar, M., Nandal, D. P. S. and Kaushik, N., Performance of wheat and mustard under Eucalyptus tereticornis based agri-silviculture system. Range Manage. Agrofor., 2013, 34(2), 192-195.

25. Pratap, R., Sharma, O. P. and Yadav, G. L., Effect of integrated nutrient management under varying levels of zinc on pearl millet yield. Ann. Arid Zone, 2008, 47(2), 197-199.

26. Anand, G. P., Mangesh and Rajkumar, M., Integrated nutrient management in carrot (Daucus Carota L.) under northeastern transitional track of Karnataka. Bioscan, 2016, 11(1), 271-273.

27. Patel, P. R., Patel, B. J., Vyas, K. G. and Yadav, B. L., Effect of integrated nitrogen management and bio-fertilizer in kharif pearl millet (Pennisetum glaucum L.). Adv. Res. J. Crop Improve., 2014 5(2), 122-125.

28. Dey, A. N., Mohanty, T. L. and Patra, S. N., Economic analysis of bamboo based agroforestry system in eastern and south eastern central plains of Orissa. Department of Forestry, Uttar Banga, Krishi Viswavidhalaya, Punidiburi, Cooch Behar (West Bengal). Indian J. For., 2007, 30, 279-282.

Received 7 August 2019; revised accepted 9 October 2019

doi: $10.18520 / \mathrm{cs} / \mathrm{v} 118 / \mathrm{i} 3 / 444-448$

\section{Energy use pattern in wheat crop production system among different farmer groups of the Himalayan Tarai region}

\author{
Rajat Kumar Sharma*, T. K. Bhattacharya, \\ Akanksha Kumain, Priyanka Chand, \\ Sandip Mandal and Deepshikha Azad \\ G.B. Pant University of Agriculture and Technology, \\ Pantnagar 263 145, India
}

This study examines the energy use pattern in wheat crop cultivation in the Himalayan Tarai region of India among different farmer groups. A total of 250 farmers from 59 villages were interviewed and information on various inputs in wheat crop production was collected during 2015-16. Based on the information, all the inputs in wheat crop production were identified and converted into energy using standard energy equivalents. Results showed that the total energy expenditure in wheat crop production in the region was $20497.1 \mathrm{MJ} / \mathrm{ha}$ in which fertilizer, fuel and seed shared $85 \%$ of the total energy. Fertilizer alone accounted for $50.2 \%$ of total energy followed by fuel $(22.6 \%)$. It was estimated that farmers of the large and medium category used more energy compared to those having small landholding, but also produced more grains. Operation-wise, fertilizer application consumed maximum energy followed by tillage operation. The average value estimated for output-to-unit input energy ratio was 3.02 , whereas it was $3.26,3.15$, 3.14, 3.11 and 2.95 for large, medium, semi-medium, small and marginal category farmers respectively. It can be concluded from the present study that energy consumption has a positive relationship with yield.

Keywords: Agriculture, energy use pattern, farmer groups, wheat crop.

MODERN-DAY agriculture crop production requires high input of fossil energy, which is consumed as 'direct energy and indirect energy (energy expended beyond the farm for the manufacture of fertilizers, plant protection agents, machines, etc. $)^{1}$. Global food security demands an increase in agriculture production as total cultivable land is decreasing and the world population is increasing day by day $^{2}$. In general, various alternatives for increasing agricultural production can be characterized in the form of additional land use, increase in yield per unit area and increased cropping intensity. As it is not possible to increase cultivable land for agriculture production, the substantial change in production may be increased by increasing the use of input resources ${ }^{3}$. Production of wheat crop directly depends on high-yielding varieties,

*For correspondence. (e-mail: rajat_sharma@hotmail.com) 


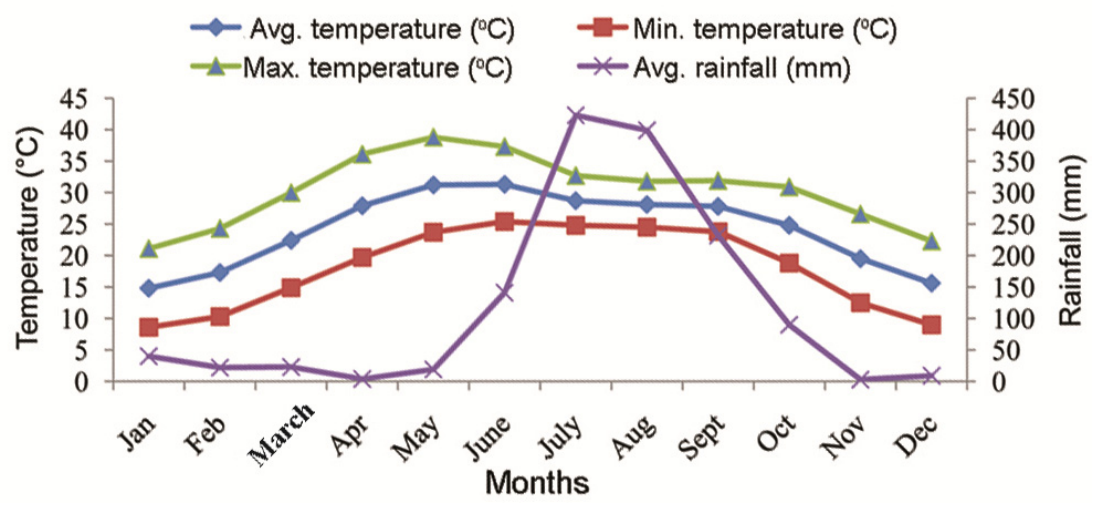

Figure 1. Average weather conditions of the Himalayan Tarai region.

agrochemicals, fertilizers, mechanization as well as on other energy inputs. Energy expenditure and crop yield in crop production vary with each input, influencing energy use efficiency ${ }^{4}$. The excessive use of inputs like fertilizers, water, fuel, agrochemicals, nutrients, electricity, etc. demands more energy in the form of human energy, animals and machinery ${ }^{5,6}$. The commercial energy consumed in Indian farming rose by $11.8 \%$ between 1980 and 2000 . Paddy and wheat make up about $75 \%$ of India's overall cereal production. The emergence of high-yielding varieties of paddy and wheat in the 1960s sparked a chain of agricultural developments that made it viable to increase food production by well over 50\% (ref. 7). Most of these agricultural changes require additional crop inputs, in particular, fossil fuel, electricity, fertilizers, agrochemicals and commercial energy. The consumption of energy and natural resources has increased because farmers have little knowledge of using more energy-efficient methods ${ }^{8}$. Use of chemical fertilizers needs to be drastically reduced. It is now well established that inorganic nitrogen fertilizer production by combining nitrogen and hydrogen at high pressure has already upset the balance between nitrates accumulating on land and aquifers, and the atmospheric nitrogen. It is affecting the planet as a whole and is therefore a serious concern.

The energy expenditure in production agriculture to raise a particular crop varies because of agro-climatic location, crop production and management practices, farm power availability, mechanization status, consumption pattern of energy inputs in different forms and other agricultural inputs ${ }^{1}$. In India, farmers are categorized as small, marginal, medium and large according to their land holding. Land-holding pattern also has significant effect on input energy use in the crop production system as management practices are different ${ }^{9}$.

Energy use pattern and energy efficiency for a particular crop vary with agro-climatic condition and mechanization status of agriculture ${ }^{3}$. Also, there is a need to study the effect of farm size on energy use pattern for crop production.
Therefore, this study was undertaken to examine the energy use of different farmer groups, which will be helpful to decide energy consumption of the region as a whole, identify the energy-intensive operations in wheat production system and provide pathways of reducing it.

The study was conducted in Udham Singh Nagar district of Uttarakhand and adjacent area of Uttar Pradesh located in the Tarai region. Figure 1 shows the average weather conditions of the growing season. Agro-ecologically, the region is classified as Zone 1: Western Himalayan Region. Tarai region in India is situated at the outer foothills of the Siwalik Hills and north of the IndoGangetic Plains. It starts from Chandigarh (foothills of the Himachal hills), and lies in Doon Valley, Bijnore, Udham Singh Nagar, Rampur, Pilibhit and Gonda districts. The Tarai belt is $15-25 \mathrm{~km}$ wide from north to south. In Uttarakhand, the Tarai region is bounded by $28^{\circ} 53^{\prime}$ and $29^{\circ} 20^{\prime} \mathrm{N}$ lat., $78^{\circ} 53^{\prime}$ and $80^{\circ} 0^{\prime} \mathrm{E}$ long., covering a total geographical area of $2908 \mathrm{sq}$. km. The common crop rotations followed are continuous rice-wheat, rice-wheat-rice, sugarcane-ratoon-wheat, rice-rapeseedsugarcane-ratoon-wheat and rice-rice-peas ${ }^{10}$. This region is considered important for wheat crop due to its higher productivity of 5-5.5 tonnes $\mathrm{ha}^{-1}$ compared to the Indian average of 3.0 tonnes/ha. Figure 2 shows demographic details of the study area.

The farmers were categorized into five groups according to their land holding (Table 1). A total of 250 farmers from 59 villages in different categories (50 from each category) were interviewed during rabi season of 2016. The information on various aspects of wheat crop production was collected by personal interviews with each selected farmer using a pre-designed questionnaire. The questionnaire was designed in such a way that it contained information about all unit operations in crop production as well as details about inventory of all resources. It included information on fertilizers, agrochemicals and farm yard manure (FYM), details of power sources (human and prime movers) and agricultural machinery as well as per hectare yield of wheat. Every crop input was 


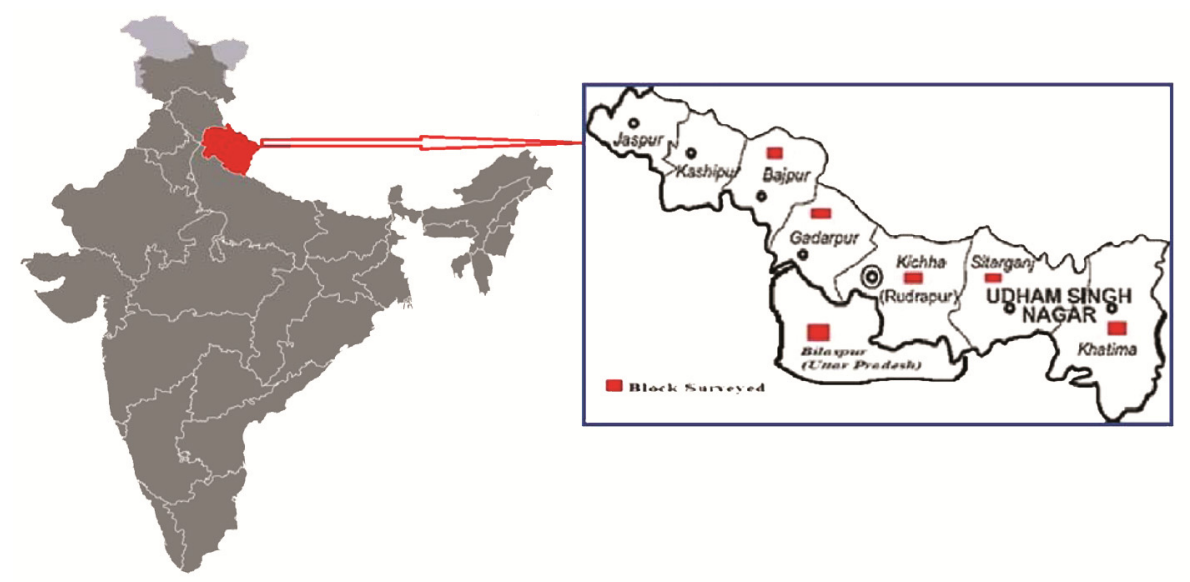

Figure 2. Map of Indian showing the study area.

Table 1. Land holding-wise category of farmers

\begin{tabular}{lc}
\hline Farmer category & Land holding (ha) \\
\hline Large & More than 10 \\
Medium & $4-10$ \\
Semi-medium & $2-4$ \\
Small & $1-2$ \\
Marginal & $0-1$ \\
\hline
\end{tabular}

Table 2. Energy coefficient for different energy inputs

\begin{tabular}{lcc}
\hline Source & $\begin{array}{c}\text { Energy equivalent (MJ) } \\
\text { Human (Man-hour) }\end{array}$ & Reference \\
Animal (pair-hour) & $\begin{array}{c}1.96 \text { adult women }=0.8 \\
\text { adult man }\end{array}$ & 22 \\
Diesel (litre) & 10.10 & 22 \\
Electricity (kWh) & 56.31 & 22 \\
Seed (kg) & 16.93 & 22 \\
Farm yard manure (kg) & 14.7 & 22 \\
& 0.3 & \\
Fertilizer & & 23 \\
$\quad$ Nitrogen (kg) & 60.6 & 23 \\
Phosphorus (kg) & 11.1 & 23 \\
Potash (kg) & 6.7 & 23 \\
Agrochemicals (kg) & 120 & 23 \\
Inferior chemicals machinery (kg) & 100 & 22 \\
$\quad$ Electric motors (kg) & 64.80 & 22 \\
Prime mover (kg) & 68.40 & 22 \\
Farm machinery (kg) & 62.10 & \\
\hline
\end{tabular}

categorized into direct and indirect energy source. Direct energy sources are human energy, fuel energy and electricity, while the indirect energy sources include seeds of high-yielding varieties, fertilizers and chemicals used in the production process, FYM and energy invested to manufacture agricultural machineries. The indirect energy sources do not have their own energy, but some energy has been invested to produce these sources. In order to estimate energy use in a particular unit operation, information on duration, amount and frequency of the unit operations and energy inputs was collected and quantified using the energy coefficient (Table 2).

The methodology adopted for the study was cradle to gate assessment, wherein some operations of the life cycle of the product such as transport and disposal of agro residue were not considered in the assessment. Therefore, the total energy expenditure assessed is that applied to the crop production system prior to the postharvest process. The study assessed the energy inputs used in the production of wheat crop only for a season without taking into account the natural sources like annual rainfall, wind, sun radiation, etc. ${ }^{11}$.

Human energy use was estimated by taking into consideration the time of labour-intensive activity and the total number of people engaged in that particular operation. The total human energy expenditure was assessed by multiplying the energy coefficient of the human power for unit man-hour by the total number of hours of human activity in the particular unit operation.

The main fuel input in wheat production was highspeed diesel (HSD), used in tractors and irrigation pump sets. In order to estimate reliable data on fuel consumption of tractors and pump sets as used by different categories of farmers, the following relationship was used ${ }^{12}$.

$$
F=\frac{\mathrm{LCF} \times \mathrm{RHP} \times \mathrm{SFC}}{1000}
$$

where $F$ is the time rate of consumption of fuel $(1 / \mathrm{h}), \mathrm{LCF}$ is the load coefficient factor (ratio of actual load on tractor to maximum load for an operation; Table 3), RHP is the rated horsepower of the source $(\mathrm{kW})$ and SFC is the brake specific fuel consumption $(\mathrm{ml} / \mathrm{kWh})$.

The values of specific fuel consumption and rated horsepower of various tractors and combine harvesters used by farmers of the region were taken from the engine 
Table 3. Load coefficient factor (LCF) for different unit operations

\begin{tabular}{llc}
\hline Power source & \multicolumn{1}{c}{ Type of work } & LCF \\
\hline Stationary diesel engine & Water-lifting & 0.6 \\
& Threshing, etc. & 0.8 \\
Tractor & Light work, e.g. transport, water-lifting etc. & 0.4 \\
& Medium work, e.g. secondary tillage, sowing & 0.5 \\
& intercultural operations, etc. & 0.6 \\
\hline
\end{tabular}

test report of the respective tractor/combine harvester published by Central Farm Machinery Training and Testing Institute (CFMTTI) Budni, MP, India. Table 3 shows the values of load coefficient factor for various power sources ${ }^{12}$.

Electricity was mainly used for pumping and irrigation. Electric motors of different ratings were found to be used by different categories of farmers for irrigation purpose. The electricity consumption by electric motor was estimated by the following relationship ${ }^{13}$.

$$
E=\mathrm{RHP} \times T,
$$

where $E$ is the total electricity expenditure $(\mathrm{kWh})$, RHP the rated horsepower of the motor $(\mathrm{kW})$ and $T$ is the total time of irrigation $(\mathrm{h})$.

The most commonly used fertilizers in India are urea, diammonium phosphate as well as super phosphate for providing nutrients like nitrogen $(\mathrm{N})$, phosphate $\left(\mathrm{P}_{2} \mathrm{O}_{5}\right)$ and potash $\left(\mathrm{K}_{2} \mathrm{O}\right)$ respectively, to the plants. In this study the amount of fertilizers applied on wheat crop was recorded by farmers' observations and therefore total N, P and $\mathrm{K}$ contents were estimated. The total energy expenditure was estimated by N, P and $\mathrm{K}$ contents of the fertilizers by the respective energy equivalents.

Similarly, energy involved in the production, packaging and transportation of agrochemicals was examined. The methodology adopted in this study to examine the agrochemical energy expenditure was to assess the amount of herbicides, insecticides and fungicides that have been applied on the wheat farms. The total chemical energy expenditure was estimated by accumulating the energy coefficient of a particular agrochemical by the total amount of that particular agrochemical applied ${ }^{20}$.

The energy expenditure to manufacture machineries such as tractors and other farm equipment was determined based on their weight, working lifespan and average annual working hours. In this study, the estimated life was used from IS:9164 (1979) $)^{21}$. The annual use of different machineries was estimated from the questionnaire, since it is the sum of total energy consumed to manufacture machineries for different unit operations for crop production. The machine energy was determined by the relationship $^{11}$.

$$
\mathrm{ME}=\frac{G \times E}{T C_{\mathrm{ef}}},
$$

where $\mathrm{ME}$ is the machine energy $(\mathrm{MJ} / \mathrm{ha}), G$ the total weight of the machinery $(\mathrm{kg}), E$ the total energy consumed in the production of agricultural equipment $(\mathrm{MJ} / \mathrm{kg}), T$ the total life span of the machine (h) and $C_{\mathrm{ef}}$ is the actual field capacity of the machine $(\mathrm{ha} / \mathrm{h})$.

After energy input, energy output was calculated based on energy equivalents of the grain. The energy indices for wheat production such as energy use efficiency and energy productivity were calculated using the following equations ${ }^{14,15}$

$$
\begin{aligned}
& \text { Net energy = Energy output }\left(\mathrm{MJ} \mathrm{ha}^{-1}\right) \\
& \text { - energy input }\left(\mathrm{MJ} \mathrm{ha}^{-1}\right),
\end{aligned}
$$

Energy use efficiency $=$ Energy output $\left(\mathrm{MJ} \mathrm{ha}^{-1}\right) /$ energy input $\left(\mathrm{MJ} \mathrm{ha}^{-1}\right)$,

Energy productivity $=$ Grain yield $\left(\mathrm{kg} \mathrm{ha}^{-1}\right) /$

$$
\text { energy input }\left(\mathrm{MJ} \mathrm{ha}^{-1}\right) \text {. }
$$

Table 4 presents the operation-wise energy consumption among different farmer groups. It includes tillage, sowing, fertilizer, interculture operation, spraying, irrigation, harvesting and threshing. Where machinery is concerned for any operation, large farmers spent much energy such as in tillage and seed-bed preparation. This is because the farmers believe that the higher number of tillage operations would prepare the field better for crop production in comparison to conservation tillage. Large number of farmers also applied higher amount of irrigation water as well as chemicals. For harvesting and threshing, energy input was higher in small land holdings due to the use of small-sized machinery which require specific energy. Table 4 shows that input energy increases with increasing land holding in a linear manner.

Many farmers consider that crop production would only increase with a higher rate of urea application. However, it is now an established fact that only a limited quantity of nitrogen used in crops is consumed by the 
Table 4. Operation-wise energy consumption pattern in wheat crop production $(\mathrm{MJ} / \mathrm{ha})$

\begin{tabular}{|c|c|c|c|c|c|c|}
\hline \multirow[b]{2}{*}{ Operation } & \multicolumn{6}{|c|}{ Category of farmers } \\
\hline & Large & Medium & Semi-medium & Small & Marginal & Weighted average \\
\hline Harrowing & 2602.3 & 2182.4 & 2020.6 & $1461.3 *$ & $1284.2 *$ & 1486.0 \\
\hline Planking & 545.0 & $361.9^{*}$ & $370.3^{*}$ & $300.9 *$ & $260.0 *$ & 291.0 \\
\hline Sowing & 2945.5 & 2804 & 2857.9 & 2895.2 & 2643.3 & 2729.9 \\
\hline Irrigation & 4192.7 & 3504.5 & $2565.9^{*}$ & $2652.8 *$ & 2779.2 & 2784.5 \\
\hline Fertilizer application & $11,208.4$ & $11,237.7$ & $10,874.9$ & 9833.1 & $10,064.5$ & $11,066.8$ \\
\hline Plant protection & 1170.8 & 1061.5 & $504.9 *$ & $518.1 *$ & $495.6 *$ & 543.2 \\
\hline Harvesting and threshing & 2217.8 & 2170.6 & 2166.6 & 2545.5 & 2503.3 & 2439.7 \\
\hline Total & $24,882.4$ & $23,322.7$ & $21,361.1$ & $20,206.9 *$ & $20,030.1^{*}$ & $20,497.1$ \\
\hline
\end{tabular}

*Significant difference at $5 \%$ level of significance.

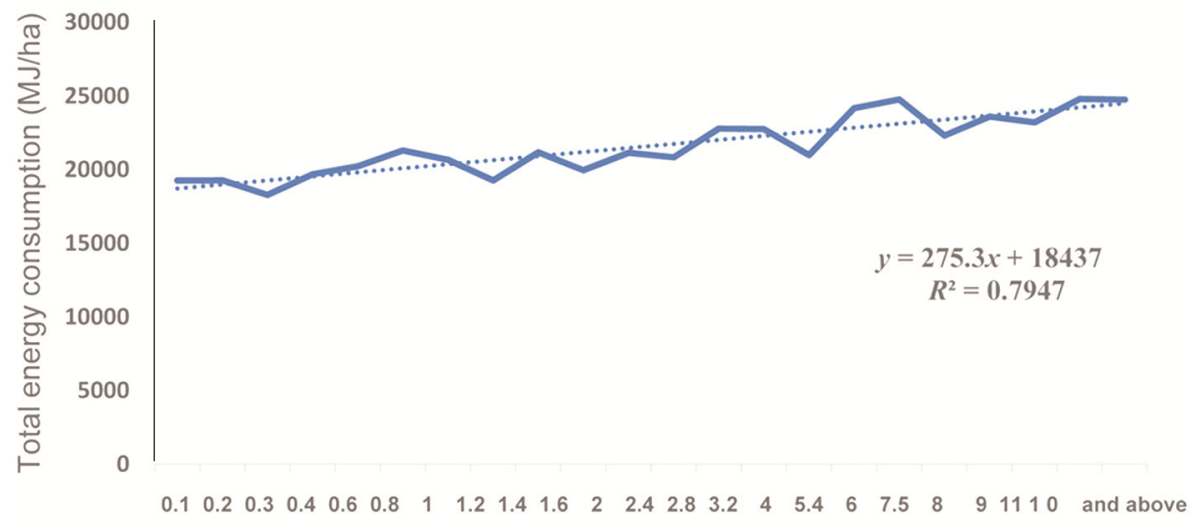

Land holding (ha)

Figure 3. Relationship between energy use pattern and land holding of the farmers.

plant itself, depending on the soil type, temperature and rainfall ${ }^{16}$.

Average operational energy consumption was observed 20,497.1 MJ/ha. It was much higher in the case of large and medium category farmers compared to small and marginal category farmers. The major difference is due to high fuel consumption and higher fertilizer application. Fertilizer application consumed maximum energy in all categories of farmers followed by harvesting and threshing. It incurred $54 \%$ of total energy consumption, which is in conformity with previous studies ${ }^{6}$.

The present study also indicates that total energy consumption has a positive relationship with land holding of the farmers (Figure 3). This may be due to the fact that farmers with larger farm size have better resources and a more mechanized agriculture production system. More mechanized agriculture system requires more fuel and electricity compared to the less mechanized system.

The total energy expenditure for wheat crop production was assessed and is presented source-wise (Table 5). As discussed above, maximum energy was consumed in fertilizer application, which accounts for 10,295 MJ/ha $(50.22 \%)$. It was observed that farmers from large and medium categories applied more fertilizers. By far, fertilizers and agro nutrients (especially urea) are the important sources of energy, followed by fuel and electricity in wheat crop production in the region. The present study and regional agronomical recommendations suggest that it is feasible to optimize energy expenditure in crop production, particularly in fertilizer application by employing improved fertilizer management system and more efficient sowing methods, such as band placement. The slowrate fertilizers can also be an efficient method of fertilizer application. The agronomical recommended dose of fertilizers for wheat crop production in the region is 150,60 and $40 \mathrm{~kg} / \mathrm{ha}$ of $\mathrm{N}, \mathrm{P}$ and $\mathrm{K}$ respectively, whereas average fertilizer application by farmers is $187.5,40$ and $20 \mathrm{~kg} / \mathrm{ha}$ respectively. This indicates that farmers in the region are applying $25 \%$ more $\mathrm{N}$ fertilizer than recommended. Nitrogen fertilizer being the most energy-intensive in the production process naturally increases the energy input in wheat production. This excessive energy consumption can be checked by applying recommended dose of $\mathrm{N}$ fertilizer. Adopting improved crop management practices such as adequate rates, appropriate sources, efficient methods of application, and application timing when crops 
RESEARCH COMMUNICATIONS

Table 5. Source-wise energy consumption pattern in wheat crop production $(\mathrm{MJ} / \mathrm{ha})$

\begin{tabular}{|c|c|c|c|c|c|c|}
\hline \multirow[b]{2}{*}{ Source } & \multicolumn{6}{|c|}{ Category of farmers } \\
\hline & Large & Medium & Semi-medium & Small & Marginal & Weighted average \\
\hline Human energy & 369.6 & 290.6 & 284.2 & 384.6 & 299.0 & 239.6 \\
\hline Fuel & 5970.2 & 5171.1 & $4711.7 *$ & 5009.9 & $4421.9 *$ & 4624.9 \\
\hline Electricity & 4114.8 & 3420.5 & $2202.2 *$ & $1693.4 *$ & $1914.1 *$ & 2030.1 \\
\hline Seed & 2435.0 & 2440.1 & 2519.5 & 2504.6 & 2577.5 & 2546.5 \\
\hline Fertilizer & $11,208.4$ & $11,237.7$ & $10,874.9$ & $9833.1 *$ & $10,064.5^{*}$ & $10,295.0$ \\
\hline Agrochemicals & 491.2 & 482.1 & 482.4 & 483.0 & 482.6 & 482.7 \\
\hline Machinery & 293.2 & 280.6 & 286.2 & 298.3 & 270.5 & 278.4 \\
\hline Total energy input & $24,882.4$ & $23,322.7$ & $21,361.1$ & $20,206.9 *$ & $20,030.1^{*}$ & $20,497.1$ \\
\hline Direct & 10,226 & 8760.1 & 7121 & 7021.4 & 6569.2 & 6894.6 \\
\hline Indirect & $14,656.6$ & $14,562.6$ & $14,240.1$ & $13,185.5$ & $13,460.9$ & $13,602.5$ \\
\hline Yield (tonnes/ha) & 5.52 & 5.00 & 4.57 & 4.27 & 4.02 & 4.22 \\
\hline Energy output & 81,144 & 73,500 & 67,179 & 62,769 & 59,094 & 62,034 \\
\hline Energy productivity (kg/MJ) & 0.222 & 0.214 & 0.214 & 0.211 & 0.201 & 0.210 \\
\hline Energy use efficiency & 3.26 & 3.15 & 3.14 & 3.11 & 2.95 & 3.02 \\
\hline
\end{tabular}

*Significant difference at $5 \%$ level of significance.

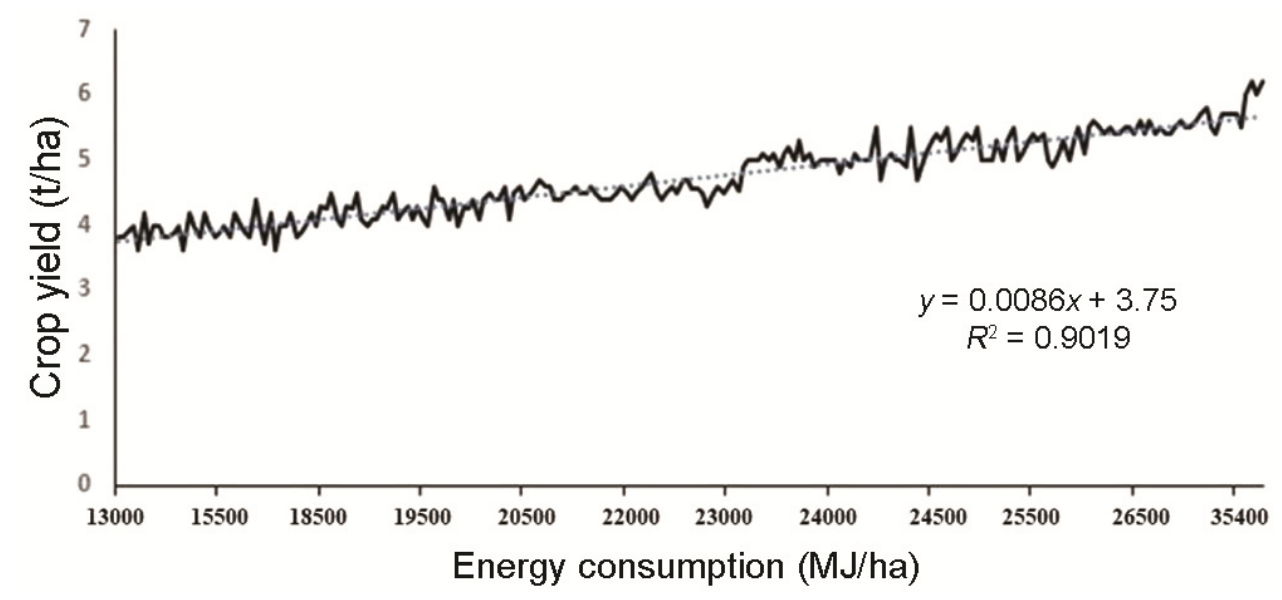

Figure 4. Effect of energy consumption on crop yield.

absorb maximum amount can increase nitrogen use efficiency in crops. Nitrogen can be applied based on field trials that determine crop responses to various rates of fertilizer application. These methods are highly efficient and effective. Further, practices such as the use of organic manure, appropriate crop rotations and conservation tillage systems also enhance crop productivity ${ }^{17}$. There is a need to reduce excessive use of fertilizers (especially urea) by large and medium farmers, and to improve the method of fertilizer application like band placement in place of broadcasting.

In comparison with other operations, tillage, and harvesting and threshing operations have the maximum proportion of fuel energy (3960 MJ/ha). These operations share $62.5 \%$ of total fuel expenditure in wheat crop production. The way to reduce fuel consumption in wheat crop production is efficient tillage methods ${ }^{18,19}$. It is an established fact that a significant amount of energy could be saved by using zero tillage or minimum tillage methods without affecting the crop yield. Energy efficiency can be achieved by adopting zero tillage or minimum tillage method ${ }^{13}$. It is obvious from the study that fuel is a major input in wheat crop production. It was observed that farmers do not adopt these tillage methods due to the problem of accumulation of standing paddy stubbles.

There is a tendency for higher energy uses to be associated with higher yield. Figure 4 shows the relationship between energy consumption and crop yield. One can observe from the figure that energy has a positive relationship with crop yield. Maximum yield was observed in the case of large and medium category farmers as they were consuming maximum energy. The results are also in agreement with previous studies ${ }^{4}$. Table 5 also shows energy ratio and energy productivity. Maximum energy ratio and energy productivity was observed in case of 


\section{RESEARCH COMMUNICATIONS}

large and medium category farmers, who were consuming more energy. It appears that to boost crop yield, extra energy should be spent. Though it is obvious from the study that energy consumption has a positive relationship with crop yield, but the effect is insignificant statistically.

Energy use efficiency in wheat crop production system varied from 3.26 to 2.95 in the region. The study shows that large and medium category farmers are more efficient than small and marginal category farmers. The energy output of large and medium category farmers was higher than other farmer categories. This may be due to the fact that the mechanization level of agriculture of large and medium category farmers is high compared to other categories, which results in better grain yield.

In this study, energy consumption in wheat crop production for each category of farmers in Himalayan Tarai region was analysed. The study showed that with increase in land holding, the energy consumption in wheat crop production increases. However, large and medium category farmers are more energy-efficient. The gap in energy use efficiency recommends increasing agriculture mechanization level for small and marginal category farmers. In wheat crop production, fertilizer is the most significant energy input followed by fuel and electricity. Therefore, we need to focus more on fertilizers, electricity and fuel consumption to reduce energy expenditure in crop cultivation compared to other factors. Special crop management practices and application procedures should be followed to increase nitrogen use efficiency. The large and medium category farmers need to be more aware of this. Also, there is a need to educate farmers about the zero tillage system by which a significant amount of energy can be saved. Proper management of these resources can reduce energy use on farms and can improve energy efficiency.

1. Hülsbergen, K. J., Feil, B., Biermann, S., Rathke, G.-W., Kalk, W.-D. and Diepenbrock, W., A method of energy balancing in crop production and its application in a long-term fertilizer trial. Agric. Ecosyst. Environ., 2001, 86(3), 303-321.

2. Pahlavan, R., Omid, M. and Akram, A., Energy input-output analysis and application of artificial neural networks for predicting greenhouse basil production. Energy, 2014, 37(1), 171-176.

3. Srivastava, N. S. L., Long-term strategies and programmes for mechanization of agriculture in agro climatic zone-V: Upper Gangetic Plains region, 2002; www.farmech.gov.in (accessed on 20 January 2017).

4. Singh, H., Singh, A. K., Kushwaha, H. L. and Singh, A., Energy consumption pattern of wheat production in India. Energy, 2007, 32, 1848-1854.

5. Lal, R., Soil carbon sequestration impacts on global climate change and food security. Science, 2004, 304, 1623-1627.

6. Singh, S. and Singh, G., Energy input versus crop yield relationship for four major crops of northern India. Agric. Mech. Asia Africa Latin Am., 1992, 23(2), 57-62.

7. Pathak, B. S. and Bining, A. S., Energy use pattern and potential for energy saving in rice-wheat cultivation. Energy Agric., 1985, 4, 271-278; 10.1016/0167-582690022-1.
8. Esengun, K., Gunduz, O. and Erdal, G., Input-output energy analysis in dry apricot production of Turkey. Energy Convers. Manage., 2007, 48, 592-598.

9. Pishgar, K. S. H., Keyhani, A., Rafiee, Sh. and Sefeedpary, P., Energy use and economic analysis of corn silage production under three cultivated area levels in Tehran province of Iran. Energy, 2011, 36(5), 3335-3341.

10. Government of Uttarakhand, Statistical Diary of Uttarakhand, Directorate of Economics and Statistics, Planning Department, 2014, pp. 46-61.

11. Safa, M., Samarasinghe, S. and Mohsen, M., A field study of energy consumption in wheat production in Canterbury, New Zealand. Energy Convers. Manage., 2011, 52(778), 2526-2536.

12. De, D., Energy use in crop production system in India, Central Institute of Agricultural Engineering, Bhopal, 2005.

13. De, D., Energy use pattern and future energy requirement for crop production by 2020. J. Agric. Eng., 2006, 43(3), 32-41.

14. Mandal, S. et al., Energy efficiency and economics of rice cultivation systems under subtropical Eastern Himalaya. Energy Sustain. Dev., 2014, 28, 115-121.

15. Singh, M. K., Pal, S. K., Thakur, R. and Verma, U. N., Energy input-output relationship of cropping systems. Indian J Agron., 1997, 67, 262-264.

16. Hirel, B., Thierry, T., Lea, P. and Dubois, F., Improving nitrogen use efficiency in crops for sustainable agriculture. Sustainability, $2011,3,1452-1485$.

17. Fageria, N. K. and Baligar, V. C., Enhancing nitrogen use efficiency in crop plants. Adv. Agron., 2005, 1(88), 97-185.

18. Aghapour, M. S. and Masihi, S., Examination of the relationship between energy consumption and performance of potato crop in cultivation under plastic in Dezful City. IJFAS, 2014, 4(53), 383389.

19. Baishya, A. and Sharma, G. L., Energy budgeting of rice-wheat cropping system. Indian J. Agron., 1990, 35, 167-177.

20. Clemens, D. R., Weise, S. F., Brown, R., Stonehouse, D. P., Hume, D. J. and Swanton, C. J., Energy analyses of tillage and herbicide inputs in alternative weed management systems. Agric. Ecosyst. Environ., 1995, 52, 119-128.

21. Indian Standard IS:9164, 1979, Guide for estimating cost of farm machinery operation.

22. Mittal, J. P. and Dhawan, K. C., Research Manual on Energy Requirements in Agricultural Sector, ICAR, New Delhi, 1988, pp. 20-33.

23. Kitani, O., Energy and Biomass Engineering. CIGR Handbook of Agricultural Engineering Vol. (V) (ed. St. Joseph), ASAE Publication, MI, USA, 1999.

ACKNOWLEDGEMENTS. We thank the ICAR-All India Coordinated Research Project on Energy in Agriculture and Agro-based Industries for funds. We also thank Mr Ankit Negi and Mr Ayush Joshi (G. B. Pant University of Agriculture and Technology, Uttarakhand) for help with the preparation of this manuscript.

Received 22 May 2019; revised accepted 20 September 2019

doi: $10.18520 / \mathrm{cs} / \mathrm{v} 118 / \mathrm{i} 3 / 448-454$ 